\title{
Characterization of a novel, ubiquitous fungal endophyte from the rhizosphere and root
}

endosphere of Populus trees

Jessica M. Vélez ${ }^{1 *}$, Timothy J. Tschaplinski ${ }^{1}$, Rytas Vilgalys ${ }^{2}$, Christopher W. Schadt $^{1}$, Gregory Bonito ${ }^{2,3}$, Khalid Hameed ${ }^{2}$, Nancy Engle ${ }^{1}$, Cyd E. Hamilton ${ }^{1,4 * \S}$

${ }^{1}$ Biosciences Division, Oak Ridge National Laboratory, Oak Ridge, TN 37831, USA,

${ }^{2}$ Department of Biology, Duke University, Durham, NC 27708, USA

${ }^{3}$ Department of Plant, Soil and Microbial Sciences, Michigan State University, East Lansing, MI 48824 USA

${ }^{4}$ Department of Civil and Environmental Engineering, University of Tennessee, Knoxville, TN. 37996

* These authors contributed equally to this work

${ }^{\S}$ Corresponding Author (email: cehdoework@gmail.com, Phone: 865574 9046, Fax: 865574 5353)

This manuscript has been authored by UT-Battelle, LLC under Contract No. DE-AC05-00OR22725 with the U.S. Department of Energy. The United States Government retains and the publisher, by accepting the article for publication, acknowledges that the United States Government retains a non-exclusive, paid-up, irrevocable, world-wide license to publish or reproduce the published form of this manuscript, or allow others to do so, for United States Government purposes. The Department of Energy will provide public access to these results of federally sponsored research in accordance with the DOE Public Access Plan (http://energy.gov/downloads/doe-public-access-plan).

(C) 2017. This manuscript version is made available under the Elsevier user license http://www.elsevier.com/open-access/userlicense/1.0/ 


\section{$1 \quad$ Abstract}

2 We examined variation in growth rate, patterns of nitrogen utilization, and competitive interactions of

3 Atractiella sp. isolated from the roots of Populus hosts. Atractiella grew significantly faster on media

4 substituted with inorganic nitrogen sources and slower in the presence of another fungal genus. To

5 determine plausible causal mechanisms we used metabolomics to explore competitive interactions

6 between Atractiella strains and Fusarium oxysporum or Leptosphaerulina chartarum. Metabolomic

7 screening of potential microbial inhibitors showed increased levels of glycosides produced in vitro by

8 Atractiella when grown with a different fungal genus, relative to when grown alone. Cumulatively, these

9 results suggest Atractiella is a poor competitor with other fungi via direct routes e.g. faster growth rates,

10 but may utilize chemical interactions and possibly nitrogen sources to defend itself, and niche partition its

11 way to abundance in the plant host root and rhizosphere.

\section{$12 \quad$ Key Words}

13 Atractiella, fungal endophytes, competition, metabolomics, organic and inorganic nitrogen, symbiosis,

14 pathogen, mutualist

15 Introduction

16 The microbiome associated with the rhizosphere of any given plant species is highly diverse and includes

17 at least some microbial species capable of spanning the symbiotic spectrum from antagonist to mutualist.

18 Plant-fungal interactions are well-documented as complex, with many fungal species demonstrating the

19 capability of shifting from plant mutualists to antagonists based on environmental context (Craven et al.

20 2001, Wicklow et al. 2005, Hartmann et al. 2008, Peay et al. 2008, Hamilton et al. 2009, Rodriguez et al.

21 2009, Hamilton et al. 2010, Kennedy et al. 2011, Wyrebek et al. 2011, Davidson et al. 2012, Hamilton

22 and Bauerle 2012, Hamilton et al. 2012, Bonito et al. 2014). The ability of a fungal endophyte to regulate

23 facets of the plant's microbiome, and therefore impact the plant host phenotype, has not been explored.

24 In vitro competitive experiments between fungal endophytes are a means of determining plausible

25 mechanisms by which interactions may occur and possibly impact plant-fungal symbiotic outcome. For

26 example, a slow-growing fungal endophyte or one with reduced competitive capabilities may be 
overwhelmed by a faster growing species when competing for space and nutrient availability within limited host niche space (Garrett 1951, Arora and Upadhyay 1978, Bennett and Lynch 1981, Whipps 2001, Bais et al. 2006, Jones et al. 2009, Taylor et al. 2014). The plant host is also capable of expressing selective preference by favoring specific fungal species, thus influencing the microbiome diversity

present in the rhizosphere and plant roots (Grayston et al. 1998, Raynaud et al. 2008, Saunders and Kohn 2008, Gottel et al. 2011, Hafidh et al. 2011).

The order Atractiellales is housed in the Pucciniomycotina and consists of three families, ten genera, and 34 species identified to date (Oberwinkler and Bandoni 1982, Aime et al. 2006, Bauer et al. 2006, Kottke et al. 2010). Our recent studies have identified several Atractiella strains as prominent root endophytes of Populus and other woody plants sampled from across a broad geographic range, including from studies of Eastern Cottonwood (P. deltoides) in Tennessee and North Carolina, and Black Cottonwood (P. trichocarpa) in Oregon and California (Gottel et al. 2011, Shakya et al. 2013, Bonito et al. 2014). Atractiella species also appear to be enriched within the root endosphere compartment, as compared to the surrounding rhizosphere. Though the Atractiellomycetes have been placed phylogenetically within the Pucciniomycotina, an order containing many rust fungi (Kottke et al. 2010), little is currently known about their ecology, and the limited evidence to date suggests these fungi may have variable life history strategies (Oberwinkler and Bandoni 1982, Oberwinkler 1989, Kottke et al. 2010, Avila-Diaz et al. 2013). For example, species of Atractiellales were first isolated from decomposing matter such as decaying potatoes (Oberwinkler and Bandoni 1982), suggesting a saprophytic life-strategy. More recently, a potential mycorrhizal-like role has been observed between Atractiellomycetes and orchids (Kottke et al. 2010, Avila-Diaz et al. 2013). This supports research showing multiple fungal genera in fungal-plant interactions are variable and dynamic in terms of the lifestrategy employed (Hamilton and Bauerle 2012, Hamilton et al. 2012). This is illustrated by organisms in the Fusarium oxysporum complex as well as the Epichloë/Neotyphodium complex (Craven et al. 2001, Clay and Schardl 2002). Fusarium oxysporum have been shown to reduce tomato plant damage caused by the pathogenic fungus Meloidogyne incognita (El-Fattah Adnan Dababat and Sikora 2007), but also 
serve as mutualistic endophytes to banana plants (Mendoza and Sikora 2009). Other F. oxysporum are

54 known to be pathogenic to members of numerous plant families, such as the Malvaceae, Solanaceae, and

55 Fabaceae (Windels 1991, Kistler 1997). Epichloë foliar endophytes can range from mutualistic to

56 pathogenic depending upon the clade (Craven et al. 2001) as well as in response to host species colonized.

57 They can also change life-strategy in response to as yet unknown triggers, within the same symbiotum

58 (Clay and Schardl 2002). Thus, there is a precedent in the literature supporting both mutualistic as well as 59 pathogenic roles for a fungal species (Veldre et al. 2013), in this case Atractiellales, to be both closely 60 related to a pathogenic order, Pucciniomycotina, and to show diverse symbiotic outcomes. The impact of 61 competition between species within the rhizosphere must also be explored, as competitors may influence 62 growth via metabolite secretions (Whipps 2001, Demirci et al. 2011). Two or more species may naturally 63 segregate to occupy separate and distinct niches which they are adapted to, decreasing competitive 64 interactions with each other (Elton 1946, Hutchinson 1957, Leibold 1995, Al-Naimi et al. 2005, Neubert 65 et al. 2006).

Limited resource availability may drive speciation and in turn alter observable species-species 67 interactions (Hutchinson 1959, Connell 1981, Leavitt et al. 2013, Winkelmann et al. 2014). The 68 efficiency and type of nitrogen $(\mathrm{N})$ used by fungi can be important for several reasons including: (1) 69 agricultural production (Reynolds et al. 2005, Jones et al. 2009, Hamilton et al. 2016), (2) understanding 70 how resource utilization impacts plant-microbial interactions (Bais et al. 2006, Harrison et al. 2007, 71 Raynaud et al. 2008, Johnson et al. 2010, Kennedy et al. 2011), and (3) increasing our understanding of 72 how microbial members of the plant microbiome interact via resource utilization (Porter and Carter 1938, 73 Bais et al. 2006, Raynaud et al. 2008, Kennedy et al. 2011, Engelmoer et al. 2014). To better understand 74 rhizosphere community dynamics, both the nitrogen used and the efficiency with which it is used by fungi 75 can be important. For example, the effects of inorganic or organic $\mathrm{N}$ sources on the growth of various 76 fungi have been repeatedly studied (Baar et al. 1997, Baar and Stanton 2000, Hodge et al. 2001, Digby et 77 al. 2010, Whiteside et al. 2012, Taylor et al. 2014) as has the impact of organic versus inorganic $\mathrm{N}$ forms 78 on fungal species biomass (Baar et al. 1997, Baar and Stanton 2000, Hodge et al. 2001, Reynolds et al. 
79

80

81 forms were preferred in in vitro studies.

Here we explore: (1) growth characteristics of a collection of Atractiella strains isolated from

83 Populus deltoides and P. trichocarpa, (2) N source utilization patterns in a model isolate, Atractiella sp.

84 (PMI 95), and (3) competitive potential of Atractiella against a panel of co-isolated Populus rhizosphere

85 fungi. In addition, we explore the potential chemical basis for competition observed from these

86 treatments via metabolomics.

\section{$87 \quad$ Materials and Methods}

$88 \quad$ Fungal strain collection and characterization

89 Twenty-three distinct strains of Atractiella species were isolated from trap-plants (Bonito et al. 2014)

90 grown in soils originating from under P. trichocarpa in a common garden experiment in Placerville,

91 California, USA (Evans et al. 2014), and wild populations of $P$. deltoides on the Yadkin River in North

92 Carolina, USA (Shakya et al. 2013). We selected a subset of Atractiella isolates to grow with a panel of

93 other potential competitor fungi isolated from the same Populus roots (Table 1). Fungal isolates were

94 obtained and maintained on Modified Melin-Norkrans (MMN) media (Marx 1969) at $20^{\circ} \mathrm{C}$. The

95 Atractiella sp., F. oxysporum and L. chartarum isolates were verified based on sequence identity of the

96 ITS1 and ITS2 region and morphological characteristics (e.g. shape of conidia, colony color). The

97 species description, systematics and population structure of the new Atractiella sp. are described in

98 Bonito et al. (2016).

99 Radial growth screening media preparation and experimental design

100 Two kinds of culture media were employed to compare fungal growth rates: PDA and P5 (Kottke et al. 101 2010, Avila-Diaz et al. 2013) agar. The P5 agar is composed of $0.5 \mathrm{~g} \mathrm{l}^{-1}$ di-ammonium tartrate, $1 \mathrm{~g} \mathrm{l}^{-1}$ 102 potassium dihydrogen phosphate, $1 \mathrm{~g} \mathrm{l}^{-1}$ magnesium sulfate heptahydrate, $5 \mathrm{~g} \mathrm{l}^{-1} \mathrm{D}(+)$-maltose, $20 \mathrm{~g} \mathrm{l}^{-1}$ $103 \mathrm{D}(+)$-glucose, $1000 \mu \mathrm{L} \mathrm{l}^{-1}$ thiamine- $\mathrm{HCl}$ solution at $100 \mathrm{mg} \mathrm{l}^{-1}, 1000 \mu \mathrm{L} \mathrm{l}^{-1}$ Kanieltra stock solution, and $10420 \mathrm{~g}^{-1}$ of agar. HIMEDIA@ $\odot$ brand PDA mix composed of $200 \mathrm{~g}$ infusion from potatoes, $20 \mathrm{~g}$ dextrose 
and $15 \mathrm{~g}$ agar was used to prepare media by suspending $30 \mathrm{~g}$ in one liter of deionized water. Cultures were grown in the dark at room temperature $\left(\sim 25^{\circ} \mathrm{C}\right)$. A flame-sterilized, metal palm inoculator was used to pull a five $\mathrm{mm}$ diameter fungal disc-shaped plug, centered in a $25 \mathrm{~mL}$ Petri dish for single colony growth rates.

\section{Qualitative competition screening of Atractiella with a panel of Populus rhizosphere isolates}

Pairwise interaction experiments were conducted between three Atractiella strains and a panel of 30 fungi co-isolated from the endosphere and rhizosphere of the same greenhouse trap-plant studies. Isolates were chosen due to the high frequency at which they were co-isolated with Atractiella. Those chosen were inoculated onto MMN media with a $0.5 \mathrm{~cm}$ diameter agar plug extracted with a cork borer from pure colonies of each fungal genus or Atractiella strain. Agar plugs of distinct genera were placed one to two $\mathrm{cm}$ apart. Interactions were then classified as negative, positive or none between Atractiella and each of the isolates assayed.

\section{Quantitative competition studies between Atractiella and Fusarium or Leptosphaerulina}

To identify potential competitive interactions, each petri dish was inoculated separately with Atractiella alone or in combination with either F. oxysporum or L. chartarum. A flame-sterilized, metal palm inoculator was used to pull a five mm diameter fungal disc-shaped plug, centered in a $25 \mathrm{ml}$ Petri dish for single colony growth rates. In order to explore fungal growth in paired fungal interactions, the five mm plugs were placed equidistant from each other and the petri dish wall. To accommodate the relatively faster radial growth rates of pathogenic fungi, mycelial plugs were added after approximately one week of Atractiella growth. Fungal colonies were measured every two to three days using an ordinal grid system to quantify rate of growth by recording growth distance from the plug's perimeter.

\section{Metabolomic profiling of interactions with Fusarium and Leptosphaerulina}

To explore differences in metabolic profiles of fungi growing alone or with a putative competitor, sample plugs of agar media were taken following the final growth measurements of Atractiella and the competitor species. Agar fungal plugs were frozen and stored at $-80^{\circ} \mathrm{C}$ prior to processing. Frozen samples were weighed into vials containing the extraction solvent, $2 \mathrm{ml}$ of $80 \%$ ethanol and $30 \mu \mathrm{l}$ of 
sorbitol (1 $\mathrm{mg} \mathrm{ml}^{-1}$ aqueous solution), and the sample weight recorded. Using internal standard differences in extraction efficiency and derivatization efficiency we corrected accordingly, and changes in sample volume during heating were included in data analysis. Samples were vortexed for several minutes until finely dispersed. Samples were allowed to extract for two hours at room temperature, after which they were syringe filtered through $0.2 \mu$ m nylon filters. One ml was dried under a stream of $\mathrm{N}_{2}$ and then dissolved in $500 \mu \mathrm{l}$ of silylation-grade acetonitrile, followed by the addition of $500 \mathrm{ml} \mathrm{N}$-methyl-Ntrimethylsilyltrifluoroacetamide (MSTFA) with 1\% trimethylchlorosilane (TMCS) (Restek, Bellefonte, PA), and then heated for one hour at $70^{\circ} \mathrm{C}$ to generate trimethylsilyl (TMS) derivatives (Li et al. 2012, Tschaplinski et al. 2012). After two days, $1 \mu$ laliquots were injected into an Agilent Technologies Inc. (Santa Clara, CA) 5975C inert XL gas chromatograph-mass spectrometer, fitted with a Restek Rtx-5MS with Integra-guard (5\% diphenyl/95\% dimethyl polysiloxane) $30 \mathrm{~m}$ x $250 \mu \mathrm{m}$ x $0.25 \mu \mathrm{m}$ film thickness capillary column. The standard quadrupole GC-MS was operated in the electron impact $(70 \mathrm{eV})$ ionization mode with gas (helium) flow set at $1 \mathrm{ml}$ per min and the injection port configured in the splitless mode. The injection port, MS Source, and MS Quad temperatures were set to $250^{\circ} \mathrm{C}, 230^{\circ} \mathrm{C}$, and $150^{\circ} \mathrm{C}$, respectively. The initial oven temperature was held at $50^{\circ} \mathrm{C}$ for $2 \mathrm{~min}$ and was programmed to increase at $20^{\circ} \mathrm{C}$ per min to $325^{\circ} \mathrm{C}$ and held for another $11 \mathrm{~min}$, before cycling back to the initial conditions. The GC-MS total ion current outputs for plugs taken from the same plate were overlapped to identify putative inhibitors produced by either of the fungi. Metabolite peak extraction, identification, and quantification were as described previously (Tschaplinski et al. 2012), and unidentified metabolites were denoted by their retention time as well as key mass-to-charge $(\mathrm{m} / \mathrm{z})$ ratios. Ratios of metabolites were determined with the data from the plug of the closest fungus used as the numerator and the more distant fungus used as the denominator, assuming that if a metabolite is higher on the side of the plate closest to one fungus, it was likely produced by that fungus.

Screening to determine the impact of organic or inorganic $N$ sources

To determine $\mathrm{N}$ content and source impacts on Atractiella 95 growth rate, the C:N ratio of P5 media was adjusted using five separate $\mathrm{N}$ source stock solutions to 100:1 in order to mimic standard P5 media C:N 
ratio, and 10:1 in order to mimic standard PDA media $\mathrm{C}: \mathrm{N}$ ratio. Three inorganic and two organic $\mathrm{N}$ source stock solutions were used to adjust the C:N ratio of P5 media to either 100:1 or 10:1 for a total of

two C: $\mathrm{N}$ ratios per $\mathrm{N}$ source. Inorganic $\mathrm{N}$ sources used included ammonium chloride, sodium nitrate, and ammonium nitrate. Organic $\mathrm{N}$ sources used included glycine and glutamate. For a 100:1 and 10:1 ratio, a total of $0.006 \mathrm{~mol} \mathrm{~L}^{-1}$ and $0.06 \mathrm{~mol} \mathrm{~L}^{-1}$ of ammonium chloride, sodium nitrate, glycine and glutamate were added to P5 media. For the same ratios with ammonium nitrate, a total of $0.003 \mathrm{~mol} \mathrm{~L}^{-1}$ and 0.03 mol L $\mathrm{L}^{-1}$ were added to P5 media.

\section{DNA extraction and PCR}

To verify the identity of the Atractiella and competitors, isolates were grown on standard PDA topped with sterilized Millipore $\odot 0.45 \mu \mathrm{m}$ membranes, allowing removal of pure fungus without agar contamination. Inoculation of plates and fungal growth on the filters was as above described. The Powerplant Pro DNA Isolation Kit@ $@$ was used to extract DNA samples as per kit instructions, and DNA samples were stored at $-20^{\circ} \mathrm{C}$. Ribosomal DNA (rDNA) was amplified using fungal-specific internal transcribed spacer (ITS) primers ITS1 and ITS4 using the ProMega GoTaq @ Master Mix kit, and cleaned using the Affymetrix, USB ExoSAP-IT @ (c) kit. Samples were Sanger sequenced on an ABI3730 Genetic Analyzer at the University of Tennessee at Knoxville (UTK), and sequences generated were analyzed against the NCBI database using BLASTN to verify identity.

\section{Data analysis of each experimental design}

All fungal growth rate analyses were completed using SAS@ software. Data were tested for normality and assumptions of heteroscedasticity both within and between treatments. When necessary, data were transformed to achieve assumptions of normality and variance distributions. A repeated-measures, generalized linear model (GLM) was used with all effects being fixed, i.e., fungal identity (Strain), date measured (Time), and media substrate (Media). Effects were evaluated individually and in all possible combinations.

\section{Results and Discussion}

Growth rate comparisons between Atractiella strains 
Radial growth rates among the nine Atractiella strains varied significantly from 1.58 to $3.18 \mathrm{~mm}$

$=5.46, \mathrm{p}=0.0002$; Table 4), as was the treatment, $\mathrm{C}: \mathrm{N}$ ratio $\left(\mathrm{F}_{1,48}=16.69, \mathrm{p}=0.0002\right.$; Table 4). After 15

$\operatorname{day}^{-1}\left(\mathrm{~F}_{6,10}=4.63, \mathrm{p}=0.0166\right.$; Table 2$)$. All fixed effects and some interactions between them were significant; Media and Strain $\left(\mathrm{F}_{6,10}=4.2, \mathrm{p}=0.0226\right.$; Table 2), Media $\left(\mathrm{F}_{1,10}=228.08, \mathrm{p}<0.0001\right.$; Table 2). On average, all Atractiella strains displayed a faster radial extension rate on PDA compared to growth on P5 media (Table 2). Time and Strain did not produce significant interaction effects $\left(\mathrm{F}_{30,50}=1.35, \mathrm{p}=\right.$ 0.1733; Table 2).

The slower growth rate on P5 media suggests nutrient limitation or auxotrophy. Interestingly, a visual assessment of Atractiella suggested comparatively faster growth rates on a nitrate-rich cellulose membrane versus a C-rich cellulose membrane, a pattern similar to that observed by Reeslev and Kjöller (1995). This suggests either Atractiella requires nitrate inputs or other chemical(s) present in the nitraterich membrane, or C-rich cellophane membranes are inhibitory. This led us to test impacts of $\mathrm{N}$ forms available to Atractiella grown on P5 media. More work needs to be done in field experiments, but this supports the hypothesis that Atractiella is, in general, a poor competitor with other fungi, yet is found in relatively high percentages in plant host roots (Bonito et al. 2014) possibly through mechanisms such as resource partitioning (Rajala et al. 2011).

Quantitative and qualitative assessments of rate of diameter change (proxy for growth rate) in Atractiella grown solo or in the presence of a putative competitor produced interesting results. For example, both Mortierella and Fusarium grew faster than the Atractiella strains they were paired with (Table 3), eventually overgrowing Atractiella colonies. Many pairings led to growth stalemates (Table 3) in which strains of Atractiella, particularly PMI 95, often produced zones of inhibition when paired with other genera (Table 3). In most interactions explored, Atractiella growth, regardless of strain, was slowed in the presence of another fungal genus (Table 3).

\section{Growth of Atractiella with organic versus inorganic $N$ sources using two C:N ratios}

Most $\mathrm{N}$ and C:N ratio treatments had a significant effect on the growth rate of Atractiella relative to control treatments (Table 4$)$. Organic versus inorganic $\mathrm{N}$ treatments were significantly different $\left(\mathrm{F}_{6,48}\right.$ 
d of growth on P5 'control' (no N source additions), the Atractiella strain 95 had a $76.14 \mathrm{~mm}$ colony diameter while $\mathrm{NH}_{4} \mathrm{Cl}$ treatments at a 10:1 C:N ratio averaged $68.79 \mathrm{~mm}$ (Fig. 1). In contrast, treatments

\section{Competition results}

The significant interaction effect between focal fungus and competitor (Table 5) suggested that regardless of competitor identity, focal fungal growth was slowed (Fig. 2), indicative of competitive interaction. Tests of individual growth responses using Tukey's Significantly Different (TSD) test showed Atractiella growth was significantly and negatively impacted by putative competitors (Table 5). In addition, qualitative analyses of interactions with multiple fungal genera support the conclusion that Atractiella, at least in vitro, is not a strong competitor. Both Mortierella and Fusarium grew comparatively rapidly and overgrew the Atractiella they were paired with (Table 2). Conversely, many pairings led to growth stalemates (Table 2). Isolates of Atractiella strains often produced zones of inhibition when paired with other fungal genera, including the basidiomycete Flagelloscypha, while melanized barrage zones were also evident in many inter-genera pairings, e.g. with Lechythophora and Ilyonectria (Table 2), suggesting Atractiella is capable of recognizing and responding to the presence of other fungal genera.

When grown solo, both $F$. oxysporum and $L$. chartarum reached colony diameters of $80 \mathrm{~mm}$ at 16 d (Fig. 3). While there were no significant differences between Atractiella strains in response to the 10 
presence of a competitor, all strains showed arrested development in the presence of different fungal genera (Tables 2. 5; Figs. 2, 3, 4). In the presence of Atractiella, both F. oxysporum and L. chartarum decreased in growth rate initially (at $3 \mathrm{~d}$ ) but recovering by the $5 \mathrm{~d}$ (Fig. 2). In addition, both competitor fungi adjusted morphologically to the presence of Atractiella by producing zones of inhibition (Figs. 2, 3). Fusarium displayed the least inhibition in response to the presence of Atractiella (Fig. 2, 3; Table 5). Whether competitive interactions resulted from competition for space, substrate resources, allelopathic interactions or some other mechanism (Porter and Carter 1938, Raynaud et al. 2008, Kennedy et al. 2011, Engelmoer et al. 2014) remains to be tested. Plausible causal mechanisms for changes in growth rate and morphology include airborne or media-infused inhibitory compounds (Garrett 1950, Arora and Upadhyay 1978, Tejesvi et al. 2007, Aly et al. 2010, Dwivedi 2013), competition for resources present in the media indirectly inhibiting growth of the adjacent fungus (Johnson et al. 2010, Engelmoer et al. 2014) or faster growth leading to a spatial impediment (Porter and Carter 1938, Raynaud et al. 2008, Kennedy et al. 2011, Engelmoer et al. 2014).

While all Atractiella colonies remained translucent when grown on P5 media, thicker aerial 249 growth developed in the presence of some N sources and concentrations. Previous reports indicated 250 bioavailability and resulting fungal biomass generated in vitro is based on $\mathrm{N}$-source present in the media 251 (Baar et al. 1997, Digby et al. 2010). Experiments with liquid media to compare fungal biomass 252 produced in response to $\mathrm{N}$ manipulations are warranted. Growth in sterile, soilless and soil mix, using 253 ergosterol techniques to measure fungal biomass, is another means of unravelling the impacts of $\mathrm{N}$ source 254 and concentration directly and indirectly on Atractiella's growth (Zill et al. 1988, Ekblad et al. 1998, 255 Mille-Lindblom et al. 2004, Kennedy et al. 2005). Additional lines of research include isotopic analysis 256 to determine how much of the $\mathrm{N}$ from various $\mathrm{N}$ sources is directly taken up by Atractiella's hyphae, and 257 how alterations in substrate or media $\mathrm{pH}$ correlate with fungal biomass production with and without 258 competition from plant roots (Six et al. 2002, Treseder et al. 2014).

259 Metabolomic profiles resulting from competitive interactions between either $F$. oxysporum or $L$. 260 chartarum in the presence of Atractiella 
To test for plausible competitive mechanisms, GC-MS was used to explore metabolite signatures. We focused the exploratory metabolite analysis on putative microbial inhibiting metabolites. Interestingly, Atractiella down-regulated all of the metabolites determined to be present (Table 6) when grown with $F$. oxysporum, but down-regulated metabolites by orders of magnitude in the presence of L. chartarum. Metabolite profiling indicated increased production of glycosides (Table 6) by Atractiella in response to the presence of other fungi and F. oxysporum and L. chartarum in response to the presence of Atractiella (Table 6). Leptosphaerulina chartarum and Atractiella both produced greatly elevated levels of 2,3butanediols, glycosides and uric acid when interacting with another fungal genera, especially $F$. oxysporum (Table 6). Glycosides are involved in a variety of metabolic activities (KEGG Orthology; http://www.genome.jp/kegg/ko.html), and have been specifically identified in plant-pathogen interactions (PATH:ko04626) involving fungal pathogen-associated molecular pattern (PAMP), and specifically PAMP-triggered immunity (Das et al. 2013). Atractiella and F. oxysporum both increased a-ediaminopimelic acid when interacting (Table 6), with the highest level closest to $F$. oxysporum, suggesting that this fungus was likely the major source of the metabolite. These results suggest that Atractiella strain 95 is stressed by the presence of $F$. oxysporum and $L$. chartarum, and also provide initial data with which to explore specific metabolites plausibly causal to competitive interactions through the PAMP pathway.

There were four related benzoxazin-3-one-like metabolites, including 2,4-dihydroxy-5-methoxy2H-1,4-benzoxazin-3-one (tentative ID), and three unknowns, including those with retention time and key mass-to-charge (m/z) ratios of 12.52234324194 249, 13.52324412163193 222, and 11.08234193 18091 (Table 6). These were produced by all three fungi, but comparatively more so by $F$. oxysporum (Table 6). Fusarium oxysporum and L. chartarum also produced 3-deoxy-D-ribo-hexitol in general, which appeared to be upregulated when interacting with Atractiella (Table 6). Specific fungal metabolic activities could potentially include ustilagic acid biosynthesis (Eveleigh et al. 1964, Teichmann et al. 2010) and antibacterial effects (Tian et al. 2016), as well as cell wall remodeling and reproduction (van 
Munster et al. 2012, van Munster et al. 2015), all common responses of fungi to stress (Fuchs and Mylonakis 2009).

In contrast, Fusarium oxysporum secreted several metabolites in response to the presence of Atractiella (Table 6). These metabolites, which include glycosides, butanediols and 2,4-dihydroxy-5methyl-2H-1,4-benzoxazin-3-one, are not secreted when $F$. oxysporum is incubated alone (Table 6), indicating these were secreted in direct response to Atractiella. Benzoxazin compounds are involved in plant stress responses and provide plants with pathogen and pest resistance (Niemeyer 1988, Morrissey and Osbourn 1999, Niemeyer 2009). There is a possibility that these same compounds serve a similar function in competitive interactions between $F$. oxysporum and Atractiella. This response may be indicative of a broader defense compound arsenal, which would explain the faster growth rate of $F$. oxysporum and positive competitive performance in vitro (Figs. 2, 3; Table 5).

Future research on Atractiella's role in the plant microbiome should focus on substrate requirements by the fungus, plant phenotype responses (i.e., plant growth, biomass, and metabolic profile) to colonization both by Atractiella alone and in combination with pathogenic fungi, as well as potential survival responses to competition employed by Atractiella, which remains abundant and ubiquitous in the Populus microbiome despite presenting as a poor competitor. Such research will help determine the impact of Atractiella on host organisms, as well as move forward the understanding of how poor competitors in a diverse microbiome remain viable and abundant.

\section{Acknowledgements}

We thank Jessy Labbé, Stephanie Soldano, Arneisha N. Jones Murray, and Zamin K. Yang for their field and laboratory work contributions. This research was sponsored by the Genomic Science Program, U.S. Department of Energy, Office of Science, Biological and Environmental Research as part of the Plant Microbe Interfaces Scientific Focus Area (http://pmi.ornl.gov). The participation of Cyd E. Hamilton was supported by a Visiting Scientist Fellowship provided by the Bioenergy Technology Office - U.S. 
Department of Energy. Oak Ridge National Laboratory is managed by UT-Battelle LLC, for the U.S.

Department of Energy under contract DE-AC05-00OR22725.

\section{References}

Aime, M. C., Matheny, P. B., Henk, D. A., Frieders, E. M., Nilsson, R. H., Piepenbring, M., McLaughlin, D. J., Szabo, L. J., Begerow, D., Sampaio, J. P., Bauer, R., Weiss, M., Oberwinkler, F., and Hibbett, D. (2006) An overview of the higher level classification of Pucciniomycotina based on combined analyses of nuclear large and small subunit rDNA sequences, Mycologia 98, 896-905.

Al-Naimi, F. A., Garrett, K. A., and Bockus, W. W. (2005) Competition, facilitation, and niche differentiation in two foliar pathogens, Oecologia 143, 449-457.

Aly, A. H., Debbab, A., Kjer, J., and Proksch, P. (2010) Fungal endophytes from higher plants: a prolific source of phytochemicals and other bioactive natural products, Fungal Divers 41, 1-16.

Arora, D. K., and Upadhyay, R. K. (1978) Effect of Fungal Staling Growth-Substances on Colony Interaction, Plant Soil 49, 685-690.

Avila-Diaz, I., Garibay-Orijel, R., Magana-Lemus, R. E., and Oyama, K. (2013) Molecular Evidence Reveals Fungi Associated within the Epiphytic Orchid Laelia Speciosa (Hbk) Schltr., Bot Sci 91, 523-529.

Baar, J., Comini, B., Elferink, M. O., and Kuyper, T. W. (1997) Performance of four ectomycorrhizal fungi on organic and inorganic nitrogen sources, Mycological research 101, 523-529.

Baar, J., and Stanton, N. L. (2000) Ectomycorrhizal fungi challenged by saprotrophic basidiomycetes and soil microfungi under different ammonium regimes in vitro, Mycological research 104, 691-697.

Bais, H. P., Weir, T. L., Perry, L. G., Gilroy, S., and Vivanco, J. M. (2006) The role of root exudates in rhizosphere interactions with plants and other organisms, Annual review of plant biology 57, 233266.

Bauer, R., Begerow, D., Sampaio, J. P., Weib, M., and Oberwinkler, F. (2006) The simple-septate basidiomycetes: a synopsis, Mycol Prog 5, 41-66.

Bennett, R. A., and Lynch, J. M. (1981) Bacterial-Growth and Development in the Rhizosphere of Gnotobiotic Cereal Plants, J Gen Microbiol 125, 95-102.

Bonito, G., Hameed, K., Toome-Heller, M., Healy, R., Yang, X., Reid, C., Liao, H.-L., Aime, M., Schadt, C., and Vilgalys, R. (2016) Atractiella rhizophila sp. nov., an endorrhizal fungus isolated from the Populus root microbiome, Mycologia in press.

Bonito, G., Reynolds, H., Robeson, M. S., Nelson, J., Hodkinson, B. P., Tuskan, G., Schadt, C. W., and Vilgalys, R. (2014) Plant host and soil origin influence fungal and bacterial assemblages in the roots of woody plants, Mol Ecol 23, 3356-3370. 
Clay, K., and Schardl, C. (2002) Evolutionary origins and ecological consequences of endophyte symbiosis with grasses, Am Nat 160, S99-S127.

Connell, J. H. (1981) Citation Classic - the Influence of Interspecific Competition and Other Factors on the Distribution of the Barnacle Chthamalus-Stellatus, Cc/Agr Biol Environ, 18-18.

Craven, K. D., Hsiau, P. T. W., Leuchtmann, A., Hollin, W., and Schardl, C. L. (2001) Multigene phylogeny of Epichloe species, fungal symbionts of grasses, Ann Mo Bot Gard 88, 14-34.

Das, B. K., Pattnaik, P., Debnath, C., Swain, D. K., and Pradhan, J. (2013) Effect of beta-glucan on the immune response of early stage of Anabas testudineus (Bloch) challenged with fungus Saprolegnia parasitica, SpringerPlus 2, 197.

Davidson, J. A., Krysinska-Kaczmarek, M., Herdina, McKay, A., and Scott, E. S. (2012) Comparison of cultural growth and in planta quantification of Didymella pinodes, Phoma koolunga and Phoma medicaginis var. pinodella, causal agents of ascochyta blight on field pea (Pisum sativum), Mycologia 104, 93-101.

Demirci, E., Dane, E., and Eken, C. (2011) In vitro antagonistic activity of fungi isolated from sclerotia on potato tubers against Rhizoctonia solani, Turk J Biol 35, 457-462.

Digby, A. L., Gleason, F. H., and McGee, P. A. (2010) Some fungi in the Chytridiomycota can assimilate both inorganic and organic sources of nitrogen, Fungal Ecology 3, 261-266.

Dwivedi, S. K. S. (2013) Fungal Succession in Composite Soil on Staled Agar Disc at different Staling Periods, Journal of Environmental Science and Technology 1, 37-42.

Ekblad, A., Wallander, H., and Nasholm, T. (1998) Chitin and ergosterol combined to measure total and living fungal biomass in ectomycorrhizas, New Phytol 138, 143-149.

El-Fattah Adnan Dababat, A., and Sikora, R. A. (2007) Induced resistance by the mutualistic endophyte, Fusarium oxysporum strain 162, toward Meloidogyne incognita on tomato, Biocontrol Science and Technology 17, 969-975.

Elton, C. (1946) Competition and the Structure of Ecological Communities, J Anim Ecol 15, 54-68.

Engelmoer, D. J. P., Behm, J. E., and Kiers, E. T. (2014) Intense competition between arbuscular mycorrhizal mutualists in an in vitro root microbiome negatively affects total fungal abundance, Mol Ecol 23, 1584-1593.

Evans, L. M., Slavov, G. T., Rodgers-Melnick, E., Martin, J., Ranjan, P., Muchero, W., Brunner, A. M., Schackwitz, W., Gunter, L., Chen, J. G., Tuskan, G. A., and DiFazio, S. P. (2014) Population genomics of Populus trichocarpa identifies signatures of selection and adaptive trait associations, Nature genetics 46, 1089-1096.

Eveleigh, D. E., Dateo, G. P., and Reese, E. T. (1964) Fungal Metabolism of Complex Glycosides Ustilagic Acid, J Biol Chem 239, 839-\&. 
Fuchs, B. B., and Mylonakis, E. (2009) Our Paths Might Cross: the Role of the Fungal Cell Wall Integrity Pathway in Stress Response and Cross Talk with Other Stress Response Pathways, Eukaryotic Cell 8, 1616-1625.

Garrett, S. D. (1950) Ecology of the Root Inhabiting Fungi, Biol Rev 25, 220-254.

Garrett, S. D. (1951) Ecological Groups of Soil Fungi: A Survey of Substrate Relationships, New Phytol 50, 149-166.

Gottel, N. R., Castro, H. F., Kerley, M., Yang, Z. M., Pelletier, D. A., Podar, M., Karpinets, T., Uberbacher, E., Tuskan, G. A., Vilgalys, R., Doktycz, M. J., and Schadt, C. W. (2011) Distinct Microbial Communities within the Endosphere and Rhizosphere of Populus deltoides Roots across Contrasting Soil Types, Appl Environ Microb 77, 5934-5944.

Grayston, S. J., Wang, S. Q., Campbell, C. D., and Edwards, A. C. (1998) Selective influence of plant species on microbial diversity in the rhizosphere, Soil Biol Biochem 30, 369-378.

Hafidh, R. R., Abdulamir, A. S., Vern, L. S., Abu Bakar, F., Abas, F., Jahanshiri, F., and Sekawi, Z. (2011) Inhibition of growth of highly resistant bacterial and fungal pathogens by a natural product, The open microbiology journal 5, 96-106.

Hamilton, C., Bever, J., Labbé, J., Yang, X., and Yin, H. (2016) An argument for increased utilization of plant microbial partners for crop production: Mitigative and adaptive opportunities to climate change via constructed microbial communities in review, Agriculture, Ecosystems \& Environment.

Hamilton, C. E., and Bauerle, T. L. (2012) A new currency for mutualism? Fungal endophytes alter antioxidant activity in hosts responding to drought, Fungal Divers 54, 39-49.

Hamilton, C. E., Dowling, T. E., and Faeth, S. H. (2010) Hybridization in Endophyte Symbionts Alters Host Response to Moisture and Nutrient Treatments, Microb Ecol 59, 768-775.

Hamilton, C. E., Faeth, S. H., and Dowling, T. E. (2009) Distribution of Hybrid Fungal Symbionts and Environmental Stress, Microb Ecol 58, 408-413.

Hamilton, C. E., Gundel, P. E., Helander, M., and Saikkonen, K. (2012) Endophytic mediation of reactive oxygen species and antioxidant activity in plants: a review, Fungal Divers 54, 1-10.

Harrison, K. A., Bol, R., and Bardgett, R. D. (2007) Preferences for different nitrogen forms by coexisting plant species and soil microbes, Ecology 88, 989-999.

Hartmann, A., Rothballer, M., and Schmid, M. (2008) Lorenz Hiltner, a pioneer in rhizosphere microbial ecology and soil bacteriology research, Plant Soil 312, 7-14.

Hawkins, H.-J., Johansen, A., and George, E. (2000) Uptake and transport of organic and inorganic nitrogen by arbuscular mycorrhizal fungi, Plant Soil 226, 275-285. 
Hodge, A., Campbell, C. D., and Fitter, A. H. (2001) An arbuscular mycorrhizal fungus accelerates decomposition and acquires nitrogen directly from organic material, Nature 413, 297-299.

Hutchinson, G. E. (1957) Concluding remarks, Cold Spring Harbor Symposia on Quantitative Biology. $22,415-427$.

Hutchinson, G. E. (1959) Homage to Santa-Rosalia or Why Are There So Many Kinds of Animals, Am Nat 93, 145-159.

Johnson, N. C., Wilson, G. W. T., Bowker, M. A., Wilson, J. A., and Miller, R. M. (2010) Resource limitation is a driver of local adaptation in mycorrhizal symbioses, P Natl Acad Sci USA 107, 2093-2098.

Jones, M. D., Grenon, F., Peat, H., Fitzgerald, M., Holt, L., Philip, L. J., and Bradley, R. (2009) Differences in $15 \mathrm{~N}$ uptake amongst spruce seedlings colonized by three pioneer ectomycorrhizal fungi in the field, Fungal Ecology 2, 110-120.

Kennedy, N., Connolly, J., and Clipson, N. (2005) Impact of lime, nitrogen and plant species on fungal community structure in grassland microcosms, Environmental microbiology 7, 780-788.

Kennedy, P. G., Higgins, L. M., Rogers, R. H., and Weber, M. G. (2011) Colonization-Competition Tradeoffs as a Mechanism Driving Successional Dynamics in Ectomycorrhizal Fungal Communities, Plos One 6.

Kistler, H. C. (1997) Genetic Diversity in the Plant-Pathogenic Fungus Fusarium oxysporum, Phytopathology 87, 474-479.

Kottke, I., Suarez, J. P., Herrera, P., Cruz, D., Bauer, R., Haug, I., and Garnica, S. (2010) Atractiellomycetes belonging to the 'rust' lineage (Pucciniomycotina) form mycorrhizae with terrestrial and epiphytic neotropical orchids, P Roy Soc B-Biol Sci 277, 1289-1298.

Leavitt, S. D., Lumbsch, H. T., Stenroos, S., and St Clair, L. L. (2013) Pleistocene Speciation in North American Lichenized Fungi and the Impact of Alternative Species Circumscriptions and Rates of Molecular Evolution on Divergence Estimates, Plos One 8.

Leibold, M. A. (1995) The Niche Concept Revisited - Mechanistic Models and Community Context, Ecology 76, 1371-1382.

Li, Y. C., Tschaplinski, T. J., Engle, N. L., Hamilton, C. Y., Rodriguez, M., Liao, J. C., Schadt, C. W., Guss, A. M., Yang, Y. F., and Graham, D. E. (2012) Combined inactivation of the Clostridium cellulolyticum lactate and malate dehydrogenase genes substantially increases ethanol yield from cellulose and switchgrass fermentations, Biotechnology for biofuels 5 .

Marx, D. H. (1969) The influence of ectotrophic mycorrhizal fungi on the resistance of pine roots to pathogenic infections. I. Antagonism of mycorrhizal fungi to root pathogenic fungi and soil bacteria, Phytopathology 59, 153-163. 
Mendoza, A. R., and Sikora, R. A. (2009) Biological control of Radopholus similis in banana by combined application of the mutualistic endophyte Fusarium oxysporum strain 162, the egg pathogen Paecilomyces lilacinus strain 251 and the antagonistic bacteria Bacillus firmus, Biocontrol 54, 263-272.

Mille-Lindblom, C., von Wachenfeldt, E., and Tranvik, L. J. (2004) Ergosterol as a measure of living fungal biomass: persistence in environmental samples after fungal death, J Microbiol Meth 59, 253-262.

Morrissey, J. P., and Osbourn, A. E. (1999) Fungal resistance to plant antibiotics as a mechanism of pathogenesis, Microbiol Mol Biol R 63, 708-+.

Neubert, K., Mendgen, K., Brinkmann, H., and Wirsel, S. G. R. (2006) Only a few fungal species dominate highly diverse mycofloras associated with the common reed, Appl Environ Microb 72, 1118-1128.

Niemeyer, H. M. (1988) Hydroxamic acids (4-hydroxy-1,4-benzoxazin-3-ones), defence chemicals in the gramineae, Phytochemistry 27, 3349-3358.

Niemeyer, H. M. (2009) Hydroxamic Acids Derived from 2-Hydroxy-2H-1,4-Benzoxazin-3(4H)-one: Key Defense Chemicals of Cereals, Journal of Agricultural and Food Chemistry 57, 1677-1696.

Oberwinkler, F., and Bandoni, R. J. (1982) Studies in Heterobasidiomycetes .13. A Taxonomic Survey of the Gasteroid, Auricularioid Heterobasidiomycetes, Can J Bot 60, 1726-1750.

Oberwinkler, F. B. R. (1989) The systematics of gasteroid, auricularioid Heterobasidiomycetes, Sydowia $56,224-256$.

Peay, K. G., Kennedy, P. G., and Bruns, T. D. (2008) Fungal Community Ecology: A Hybrid Beast with a Molecular Master, Bioscience 58, 799-810.

Porter, C. L., and Carter, J. C. (1938) Competition among fungi, The Botanical Review 4, 165-182.

Rajala, T., Peltoniemi, M., Hantula, J., Mäkipää, R., and Pennanen, T. (2011) RNA reveals a succession of active fungi during the decay of Norway spruce logs, Fungal Ecology 4, 437-448.

Raynaud, X., Jaillard, B., and Leadley, P. W. (2008) Plants may alter competition by modifying nutrient Bioavailability in rhizosphere: A modeling approach, Am Nat 171, 44-58.

Reeslev, M., and Kjoller, A. (1995) Comparison of Biomass Dry Weights and Radial Growth-Rates of Fungal Colonies on Media Solidified with Different Gelling Compounds, Appl Environ Microb 61, 4236-4239.

Reynolds, H. L., Hartley, A. E., Vogelsang, K. M., Bever, J. D., and Schultz, P. A. (2005) Arbuscular mycorrhizal fungi do not enhance nitrogen acquisition and growth of old-field perennials under low nitrogen supply in glasshouse culture, New Phytol 167, 869-880. 
Rodriguez, R. J., White, J. F., Arnold, A. E., and Redman, R. S. (2009) Fungal endophytes: diversity and functional roles, New Phytol 182, 314-330.

Saunders, M., and Kohn, L. M. (2008) Host-synthesized secondary compounds influence the in vitro interactions between fungal endophytes of maize, Appl Environ Microb 74, 136-142.

Shakya, M., Gottel, N., Castro, H., Yang, Z. M. K., Gunter, L., Labbe, J., Muchero, W., Bonito, G., Vilgalys, R., Tuskan, G., Podar, M., and Schadt, C. W. (2013) A Multifactor Analysis of Fungal and Bacterial Community Structure in the Root Microbiome of Mature Populus deltoides Trees, Plos One 8.

Six, J., Feller, C., Denef, K., Ogle, S. M., Sa, J. C. D., and Albrecht, A. (2002) Soil organic matter, biota and aggregation in temperate and tropical soils - Effects of no-tillage, Agronomie 22, 755-775.

Taylor, D. L., Hollingsworth, T. N., McFarland, J. W., Lennon, N. J., Nusbaum, C., and Ruess, R. W. (2014) A first comprehensive census of fungi in soil reveals both hyperdiversity and fine-scale niche partitioning, Ecol Monogr 84, 3-20.

Teichmann, B., Liu, L. D., Schink, K. O., and Bolker, M. (2010) Activation of the Ustilagic Acid Biosynthesis Gene Cluster in Ustilago maydis by the $\mathrm{C} 2 \mathrm{H} 2$ Zinc Finger Transcription Factor Rua1, Appl Environ Microb 76, 2633-2640.

Tejesvi, M. V., Kini, K. R., Prakash, H. S., Subbiah, V., and Shetty, H. S. (2007) Genetic diversity and antifungal activity of species of Pestalotiopsis isolated as endophytes from medicinal plants, Fungal Divers 24, 37-54.

Tian, J.-F., Li, P.-J., Li, X.-X., Sun, P.-H., Gao, H., Liu, X.-Z., Huang, P., Tang, J.-S., and Yao, X.-S. (2016) New antibacterial isocoumarin glycosides from a wetland soil derived fungal strain Metarhizium anisopliae, Bioorganic \& Medicinal Chemistry Letters 26, 1391-1396.

Treseder, K. K., Bent, E., Borneman, J., and McGuire, K. L. (2014) Shifts in fungal communities during decomposition of boreal forest litter, Fungal Ecology 10, 58-69.

Tschaplinski, T. J., Standaert, R. F., Engle, N. L., Martin, M. Z., Sangha, A. K., Parks, J. M., Smith, J. C., Samuel, R., Jiang, N., Pu, Y., Ragauskas, A. J., Hamilton, C. Y., Fu, C., Wang, Z. Y., Davison, B. H., Dixon, R. A., and Mielenz, J. R. (2012) Down-regulation of the caffeic acid Omethyltransferase gene in switchgrass reveals a novel monolignol analog, Biotechnology for biofuels 5, 71 .

van Munster, J. M., Nitsche, B. M., Akeroyd, M., Dijkhuizen, L., van der Maarel, M. J. E. C., and Ram, A. F. J. (2015) Systems Approaches to Predict the Functions of Glycoside Hydrolases during the Life Cycle of Aspergillus niger Using Developmental Mutants $\triangle b r l A$ and $\triangle$ flbA, Plos One 10, e0116269. 
van Munster, J. M., van der Kaaij, R. M., Dijkhuizen, L., and van der Maarel, M. J. E. C. (2012) Biochemical characterization of Aspergillus niger CfcI, a glycoside hydrolase family 18 chitinase that releases monomers during substrate hydrolysis, Microbiology 158, 2168-2179.

Veldre, V., Abarenkov, K., Bahram, M., Martos, F., Selosse, M.-A., Tamm, H., Kõljalg, U., and Tedersoo, L. (2013) Evolution of nutritional modes of Ceratobasidiaceae (Cantharellales, Basidiomycota) as revealed from publicly available ITS sequences, Fungal Ecology 6, 256-268.

Whipps, J. M. (2001) Microbial interactions and biocontrol in the rhizosphere, Journal of experimental botany $52,487-511$.

Whiteside, M. D., Digman, M. A., Gratton, E., and Treseder, K. K. (2012) Organic nitrogen uptake by arbuscular mycorrhizal fungi in a boreal forest, Soil Biology and Biochemistry 55, 7-13.

Wicklow, D. T., Roth, S., Deyrup, S. T., and Gloer, J. B. (2005) A protective endophyte of maize: Acremonium zeae antibiotics inhibitory to Aspergillus flavus and Fusarium verticillioides, Mycological research 109, 610-618.

Windels, C. E. (1991) Current Status of Fusarium Taxonomy, Phytopathology 81, 1048-1051.

Winkelmann, K., Genner, M. J., Takahashi, T., and Ruber, L. (2014) Competition-driven speciation in cichlid fish, Nat Commun 5.

Wyrebek, M., Huber, C., Sasan, R. K., and Bidochka, M. J. (2011) Three sympatrically occurring species of Metarhizium show plant rhizosphere specificity, Microbiol-Sgm 157, 2904-2911.

Zill, G., Engelhardt, G., and Wallnofer, P. R. (1988) Determination of ergosterol as a measure of fungal growth using Si 60 HPLC, Zeitschrift fur Lebensmittel-Untersuchung und -Forschung 187, 246249. 
Fig 1 Total colony diameter of Atractiella 95 when plated on unmodified P5 and PDA media as well as

534 P5 with inorganic or organic N sources. Inorganic and organic N sources are compared at the 10:1 C:N 535 ratio (left) versus the 100:1 C:N ratio (right). Bars represent standard errors.

Fig 2 Atractiella, F. oxysporum and L. chartarum growth in response to the presence of a competitor.

537 Fig 3 Total colony diameter with the focal fungus indicated underneath each grouping. Diameter is

538 shown at $8 \mathrm{~d}$. The same general pattern was produced at all time points measured (data not shown). Bars 539 represent standard errors.

540 Fig 4 Atractiella growth inhibition was observed by $2 \mathrm{~d}$ measurements after the addition of the two 541 competitor fungus. Atractiella is growing on the right in both images with the central $2 \mathrm{~mm}$ diameter 542 plug visible. Leptosphaerulina chartarum is the competitor species on the left. Images are the upper (A) 543 and lower (B) side of the plate. 
Fig 1

83
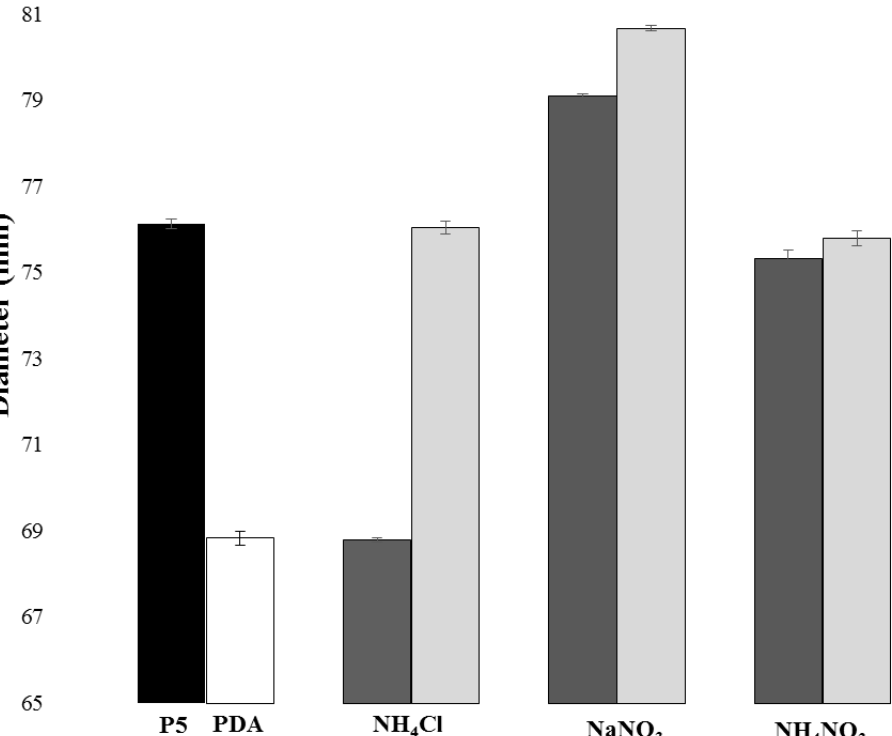

$\mathrm{NaNO}_{3}$

$\mathrm{NH}_{4} \mathrm{NO}_{3}$

Glycine

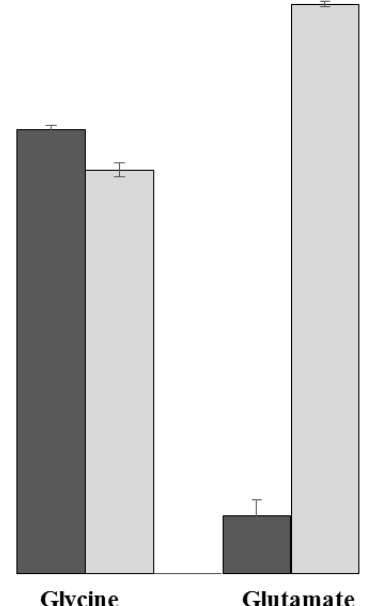

Glutamate

Total Colony Diameter per Treatment (mm) 
Fig 2

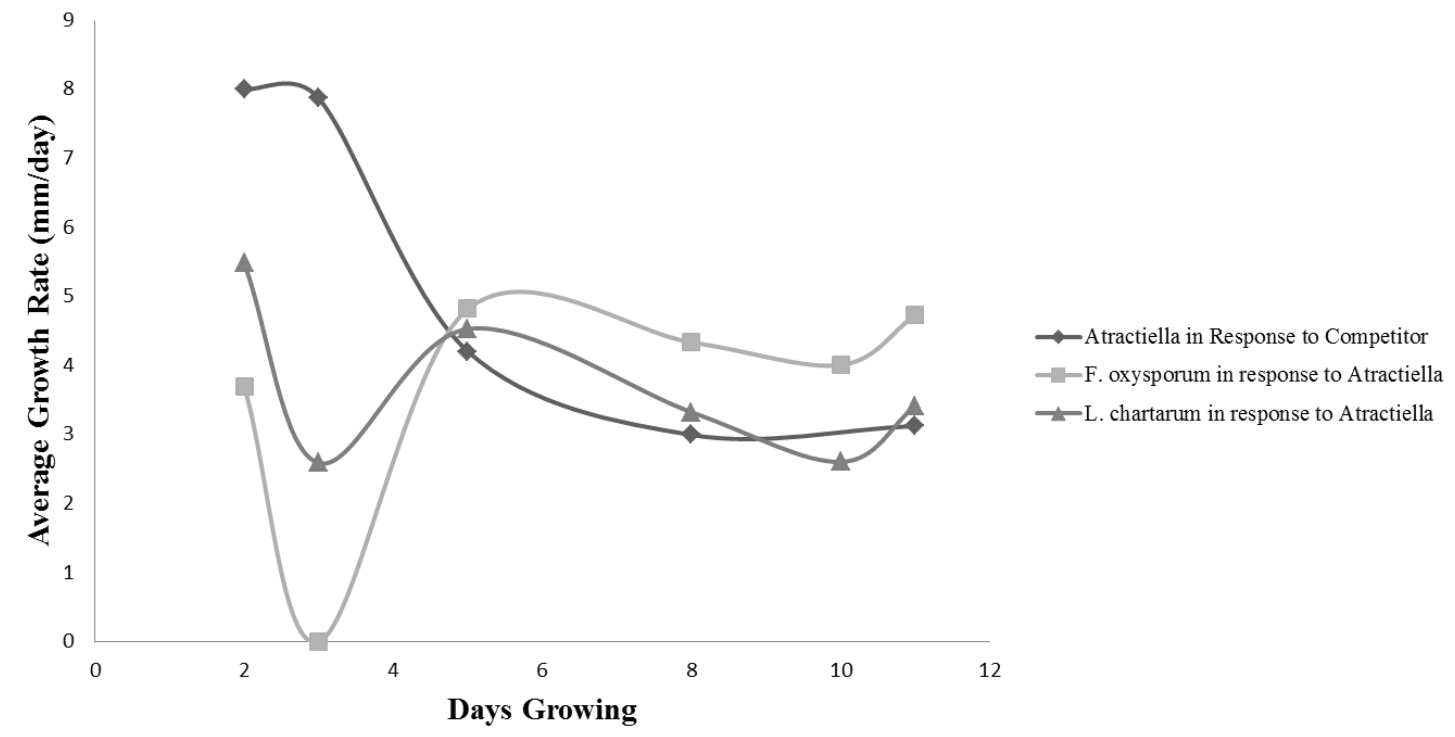


Fig 3

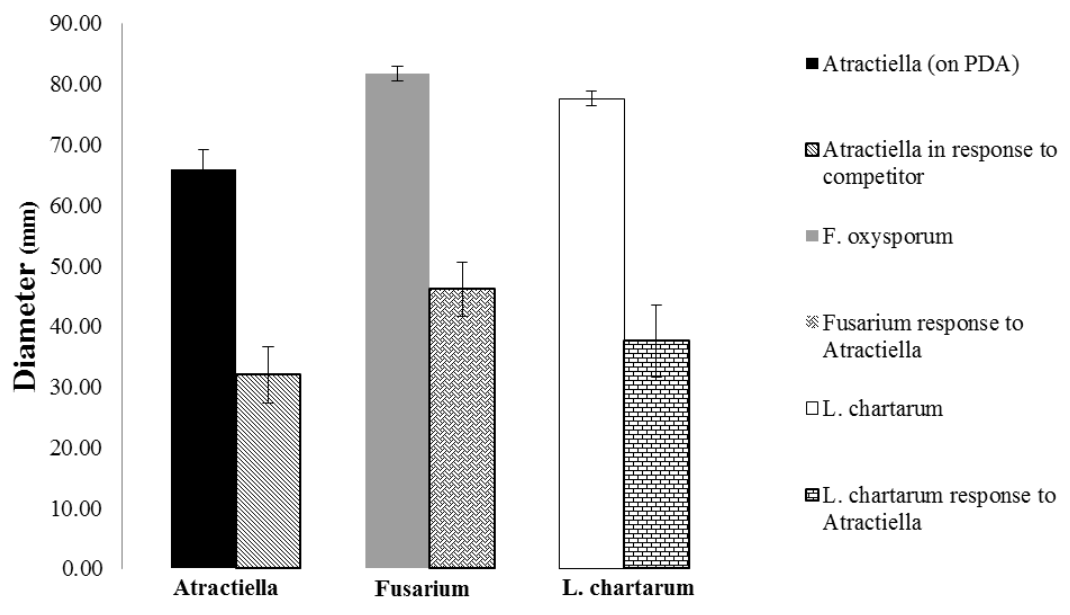

Average Colony Diameter per Species (mm) 
Fig 4

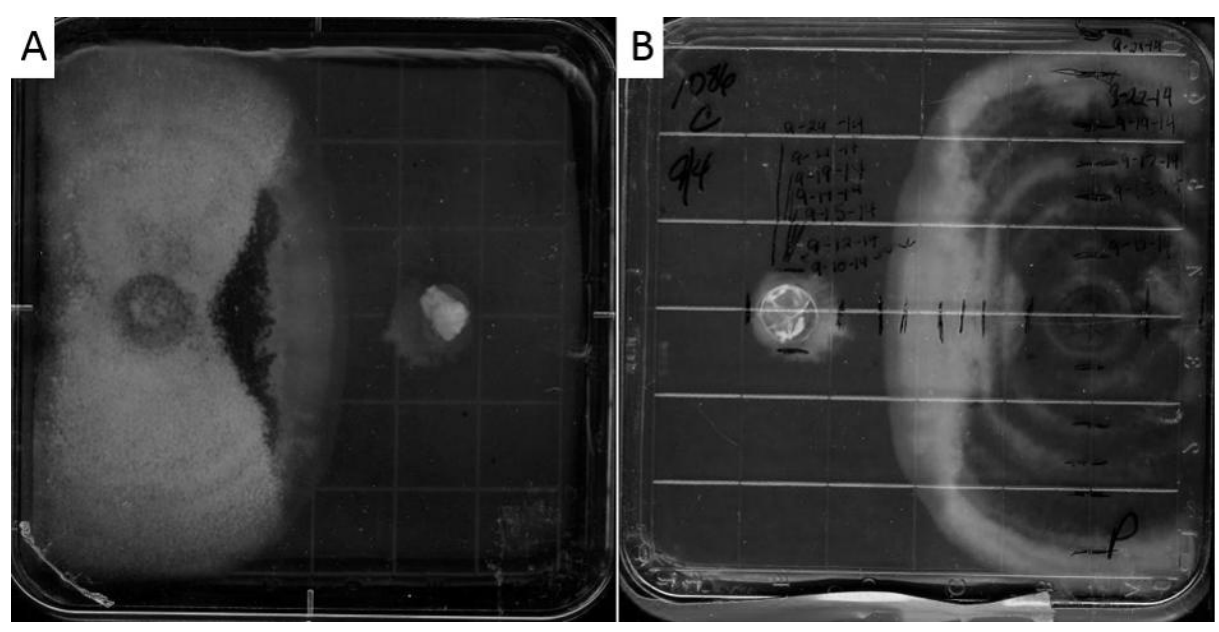


Table 1: Geographic origin and Populus trap plant hosts from which the Atractiella strains were collected from root tissues. Strains used in this study are bolded.

\begin{tabular}{|c|c|c|}
\hline Strain & Origin of Soil & Trap Plant Host \\
\hline 95 & North Carolina (with P. deltoides) & P. deltoides \\
\hline 152 & North Carolina (with P. deltoides) & P. deltoides \\
\hline 1054 & California (with $P$. trichocarpa) & P. trichocarpa \\
\hline 1086 & California (with P. trichocarpa) & P. trichocarpa \\
\hline 1114 & California (with $P$. trichocarpa) & P. trichocarpa \\
\hline 1119 & California (with $P$. trichocarpa) & P. trichocarpa \\
\hline 1138 & California (with $P$. trichocarpa) & P. trichocarpa \\
\hline 1140 & California (with $P$. trichocarpa) & P. trichocarpa \\
\hline 1142 & California (with $P$. trichocarpa) & P. trichocarpa \\
\hline 1145 & California (with $P$. trichocarpa) & P. trichocarpa \\
\hline 1148 & California (with $P$. trichocarpa) & P. trichocarpa \\
\hline 1152 & California (with P. trichocarpa) & P. trichocarpa \\
\hline 1165 & California (with $P$. trichocarpa) & P. trichocarpa \\
\hline 1165.2 & California (with P. trichocarpa) & P. trichocarpa \\
\hline 1176 & California (with P. trichocarpa) & P. trichocarpa \\
\hline 1180 & California (with $P$. trichocarpa) & P. trichocarpa \\
\hline 1199 & California (with $P$. trichocarpa) & P. trichocarpa \\
\hline 1210 & California (with P. trichocarpa) & P. trichocarpa \\
\hline
\end{tabular}




$\begin{array}{lll}1580 & \text { North Carolina (with P. deltoides) } & \text { P. ponderosa } \\ \mathbf{1 5 8 7} & \text { North Carolina (with P. deltoides) } & \text { P. trichocarpa } \\ \mathbf{1 6 4 5} & \text { North Carolina (with P. deltoides) } & \text { P. trichocarpa } \\ 1656 & \text { North Carolina (with P. deltoides) } & \text { P. trichocarpa } \\ 1678 & \text { North Carolina (with P. deltoides) } & \text { P. trichocarpa } \\ & \text { North Carolina (with P. deltoides) } & \text { P. trichocarpa }\end{array}$


Table 2: All strains of Atractiella produced significantly different growth rates in response to media type.

\begin{tabular}{lllll}
\hline Effect & Num df & den df & F & P \\
\hline Time & 5 & 50 & 12.88 & $<0.0001$ \\
Strain & 6 & 10 & 4.63 & 0.0166 \\
Time X Strain & 30 & 50 & 1.35 & 0.1733 \\
Media & 1 & 10 & 228.08 & $<0.0001$ \\
Strain X Media & 6 & 10 & 4.2 & 0.0226
\end{tabular}


Table 3: A summary of the single pair interactions performed between Atractiella and co-isolated fungal taxon from Populus. A + designation indicates Atractiella out-competed the co-isolate, a - indicates Atractiella was out-competed by the co-isolate, and 0 indicates no observed effect on growth of either Atractiella or the co-isolate.

\begin{tabular}{|c|c|c|c|}
\hline \multicolumn{4}{|c|}{ Single Pair Interactions Table of Atractiella versus a Co-Isolate } \\
\hline Paired Species & Atractiella - PMI 152 & $\begin{array}{l}\text { Atractiella - PMI } \\
95\end{array}$ & $\begin{array}{l}\text { Atractiella - } \\
\text { PMI252 }\end{array}$ \\
\hline Pleosporales - PMI 150 & - & - & - \\
\hline Ilyonectria - PMI 151 & 0 & 0 & 0 \\
\hline Ilyonectria - PMI 153 & + & + & 0 \\
\hline Ilyonectria - PMI 154 & + & + & + \\
\hline Pleosporales PMI 155 & - & 0 & - \\
\hline Phialocephala - PMI 193 & + & + & + \\
\hline Mortierella PMI 93 & - & - & - \\
\hline Thelephoraceae PMI 130 & + & + & + \\
\hline Sordariomycete PMI 145 & + & 0 & 0 \\
\hline Pleosporales - PMI 146 & + & + & + \\
\hline Fusarium - PMI 11 & - & - & - \\
\hline Umbellopsis - PMI 12 & 0 & 0 & 0 \\
\hline Corticiales - PMI 14 & 0 & 0 & 0 \\
\hline Ilyonectria - PMI 122 & - & $0 /-$ & - \\
\hline Mariannaea - PMI 123 & 0 & 0 & 0 \\
\hline Sordariomycete - PMI 1 & 0 & 0 & 0 \\
\hline Sordariomycete - PMI 3 & 0 & 0 & 0 \\
\hline Sordariales - PMI 4 & 0 & 0 & 0 \\
\hline Ilyonectria - PMI 6 & - & - & - \\
\hline
\end{tabular}




$\begin{array}{cccc}\text { Ilyonectria - PMI } 7 & - & - \\ \text { Ilyonectria - PMI } 83 & - & 0 & 0 /- \\ \text { Mortierella PMI } 85 & - & 0 /- & - \\ \text { Mortierella PMI } 86 & - & - & 0 \\ \text { Ilyonectria - PMI } 91 & 0 & 0 & + \\ \text { Heliotiales - PMI } 350 & + & + & 0 /- \\ \text { Clavulina - PMI } 390 & 0 /- & 0 & 0 \\ \text { Leptodontidium - PMI } 454 & 0 & 0 & 0 /+ \\ \text { Sordariomycete - PMI } 493 & 0 /- & 0 /- & 0 /- \\ \text { Flagelloscypha - PMI526 } & 0 /- & 0 & 0 \\ \text { Sordariomycete - PMI } 527 & 0 & \end{array}$


Table 4: All effects were significant separately and in combination, with the $\mathrm{C}: \mathrm{N}$ ratio having the largest impact on Atractiella growth rate.

\begin{tabular}{llll}
\hline Effect & DF & F Value & p Value \\
\hline Treatment & 6 & 5.46 & 0.0002 \\
C:N Ratio & 1 & 16.69 & 0.0002 \\
Treatment x C:N Ratio & 4 & 3.51 & 0.0137
\end{tabular}


Table 5: Comparison of growth rate in response to identity of focal fungus (Atractiella, F. oxysporum or L. chartarum) and competitor presence or absence.

\begin{tabular}{llll}
\hline Effect & $\mathrm{df}$ & $\mathrm{T}$ & Tukey's adjusted p \\
\hline Atractiella/F. oxysporum versus Atractiella alone & 10 & -2.76 & 0.0201 \\
F. oxysporum/Atractiella versus F. oxysporum alone & 10 & -2.49 & 0.0322 \\
Atractiella/L. chartarum versus Atractiella alone & 10 & -3.3 & 0.008 \\
L. chartarum/Atractiella versus L. chartarum alone & 10 & -2.52 & 0.0303 \\
Atractiella alone & 10 & -2.4 & 0.037 \\
F. oxysporum alone & 10 & -3.71 & 0.004 \\
L. chartarum alone & 10 & -4.29 & 0.0016
\end{tabular}


Table 6: Metabolite prevalence in $\mathrm{mg} \mathrm{g}^{-1}$ as determined by GC-MS analysis. Determination of significant differences was not tested on account of a small total sample size.

\begin{tabular}{|c|c|c|c|c|c|c|c|c|c|}
\hline & \multicolumn{6}{|c|}{ Identified Metabolites } & \multicolumn{3}{|c|}{$\begin{array}{l}\text { Unidentified } \\
\text { Metabolites }\end{array}$} \\
\hline Sample ID & $\begin{array}{l}3- \\
\text { deox } \\
\text { y-D- } \\
\text { ribo- } \\
\text { hexit } \\
\text { ol }\end{array}$ & $\begin{array}{l}2,4- \\
\text { dihydrox } \\
\text { y-5- } \\
\text { methyl- } \\
2 \mathrm{H}-1,4- \\
\text { benzoxaz } \\
\text { in-3-one }\end{array}$ & $\begin{array}{l}\text { uri } \\
\mathrm{c} \\
\text { aci } \\
\text { d }\end{array}$ & $\begin{array}{l}\text { a-e- } \\
\text { diaminopim } \\
\text { elic acid }\end{array}$ & $\begin{array}{l}\text { butanedi } \\
\text { ols }\end{array}$ & $\begin{array}{l}523538 \\
\text { glycosid } \\
\text { es }\end{array}$ & $1^{\mathrm{a}}$ & $2^{\mathrm{b}}$ & $3^{c}$ \\
\hline $\begin{array}{l}F . \\
\text { oxysporum/Atract } \\
\text { iella }\end{array}$ & 50.4 & 17.3 & 1.7 & 19 & 25.9 & 143 & 33.9 & 27.1 & 3.9 \\
\hline $\begin{array}{l}\text { Atractiella/F. } \\
\text { oxysporum }\end{array}$ & 21 & 8.4 & 1 & 37.1 & 56.4 & 76.9 & 14.2 & 12.4 & 1.6 \\
\hline F. Oxysporum & 15.1 & 62.5 & 0 & 0 & 0 & 0 & 113.9 & 120.8 & 31.3 \\
\hline $\begin{array}{l}\text { L. } \\
\text { chartarum/Atract } \\
\text { iella }\end{array}$ & 13.3 & 0 & 0.3 & 0 & 3 & 424 & 0 & 0.2 & 0 \\
\hline $\begin{array}{l}\text { Atractiella/L. } \\
\text { chartarum }\end{array}$ & 3.7 & 0 & 0.3 & 0 & 2.3 & 426.7 & 0 & 0.2 & 0 \\
\hline L. chartarum & 6 & 1.1 & 0.3 & 0 & 15.4 & 109.8 & 1.1 & 1.2 & 0.3 \\
\hline Atractiella & 0 & 0.9 & 0.1 & 0 & 0.4 & 0.5 & 1.3 & 0.8 & 0.2 \\
\hline
\end{tabular}

${ }^{\mathrm{a}}$ Unidentified metabolite 1 ID number: 12.52234324194 249. ${ }^{\mathrm{b}}$ Unidentified metabolite 2 ID number: 13.52324412163193222 . ' Unidentified metabolite 3 ID number: 11.082341931809. 